\title{
Acquisition of a passive avoidance response as determined by variations in prior aversive stimulation'
}

\author{
D. ChRis ANDERSON2, H. W. TYSON AND F, WILLIAMS 3 \\ THE MENNINGER FOUNDATION
}

The effects of various forms of prior enforced sleep $\mathrm{Td}$ (SD) and of pre-shock (PS), as presumed traumatizing agents, were studied in rats 15 days following treatment using an approach-avoidance test procedure involving successive response to food, mild punishment, food, and weak punishment. PS Ss and Ss whose SD treatment involved prolonged walking on un abrasive surface exhibited greater avoidance of the food area to mild punishment than controls, while $S s$ whose SD treatment consisted of prolonged walking on a smooth surface or prolonged standing in deep water exhibited significantly less conflict. With one exception, similar results were obtained under the weak test punishment.

Pearl, Walter, \& Anderson (1964) found that rats who were subjected to prior enforced sleep deprivation (SD) more rapidly acquired a passive avoidance response (PAR) relative to non-SD controls in an approachavoidance conflict test situation. To analyze this result the present study was designed to evaluate the following possible explanations: (1) Sore feet, resulting from enforced prolonged walking on abrasive hardware cloth, may have provided cues which became conditioned to the rolling semi-tumbling response observed near the end of the SD treatment. Subsequent shock to the feet in the test situation may have been enough like the painful SD condition to elicit similar behavior incompatible with the approach response; (2) Prolonged enforced exercise may have had a traumatizing effect similar to that of pre-shock (PS) as also reported by Pearl et al (1964); (3) SD per se conceivably may have been traumatizing; (4) All of the above three variables may have worked in concert to produce a prolonged state of overarousal, which, in turn, servedas a severe trauma (cf. Malmo, 1957). A PS group was included in order to directly compare the effects of two qualitatively different forms of aversive stimulation on subsequent responses to punishment.

Method

The Ss were 50 naive, 90 days old, male albino rats maintained in The Menninger Foundation colony. The PS chamber was similar to that described elsewhere (Kurtz \& Pearl, 1960). The SD apparatus was a circular drum divided into five $10 \mathrm{in}$. in diameter by $7 \mathrm{in}$. wide compartments. The test apparatus, described in detail elsewhere (Brown \& Hoopes, 1965), was a straight alley, and provided graphic determinations of the point at which S first stopped approaching, etc. Running times were recorded by a system of photo-relays and clocks. The test shock was the 60 cycle output of a variable autotransformer through a $20 \mathrm{~K}$ resistor. The treatment shock source was a $7500 \mathrm{v}$ neon transformer through a $6 \mathrm{M}$ resistor.

The study was mun in 2 replications of $25 \mathrm{Ss}$ each. Three groups of $10 \mathrm{Ss}$ were SD. One SD treatment duplicated that of Pearl et al (1964), and involved 30 $\mathrm{hr}$. of $\mathrm{SD}$ in the drum on hardware cloth $\left(\mathrm{SD}_{\mathrm{a}}\right)$ at 5.7 rpm over a $31 \mathrm{hr}$. period $(1 \mathrm{hr}$. of non-rotation was inserted for eating and drinking at the end of the first $24 \mathrm{hr}$.). The drum floor was covered with polyethelene to minimize sore feet while administering an otherwise equivalent $\mathrm{SD}$ treatment to another group $\left(\mathrm{SD}_{\mathrm{S}}\right)$. The Ss of Group $\mathrm{SD}_{\mathrm{S}}$ did not develop foot blisters as did Ss of Group $\mathrm{SD}_{\mathrm{a}}$. By the 8 th day following treatment, the paws of the $\mathrm{SD}_{\mathrm{a}}$ Ss had healed. To control both for sore paws and prolonged walking, a third group ( $\mathrm{SD}_{\mathrm{W}}$ ) was forced to remain awake by standing on small $1-1 / 2$ sq. in. pedestles located 1 in. below the surface of 9 in. deep water. A preliminary study indicated that the $\mathrm{SD}_{\mathrm{W}}$ Ss would remain awake for the $30 \mathrm{hr}$. period.

The PS Ss each received nine $5 \mathrm{sec}$. free shocks randomly spaced over a $30 \mathrm{~min}$. period. The C Ss were handled and confined in the SD or PS apparatus for durations comparable to experimental $\mathrm{Ss}$, but were neither rotated nor shocked.

Nine days after treatment, Ss were placed on food Td, reduced to $80 \%$ body weight (maintained during the rest of the study), and then administered 61 alley food training trials spaced over 7 days. On the following day all Ss were given 2 or 3 mild shocks $(0.5$ sec. at $50 \mathrm{v}$ ) in the goal area of the alley (equated for groups). Three recovery trials per day were given thereafter until all groups were again equal in running times. A second test session was marked by again subjecting all Ss to weak shock (0.3 sec. at $40 \mathrm{v})$ as they entered the goal area on each of the next 5 consecutive trials. Food was available on all test shock and shock-recovery trials.

Results

Mean group running times were identical for the last 10 acquisition trials ( $\mathrm{F}=<1$ ). To reduce heterogeneity and skewness running times for all test trials were converted to logarithms. Figure 1 portrays group log running times, averaged and analyzed for each trial, on each of the three days following the initial mild test shock. Several major conclusions are represented in this figure and were supported by a 5 by 3 by 3 factorial 


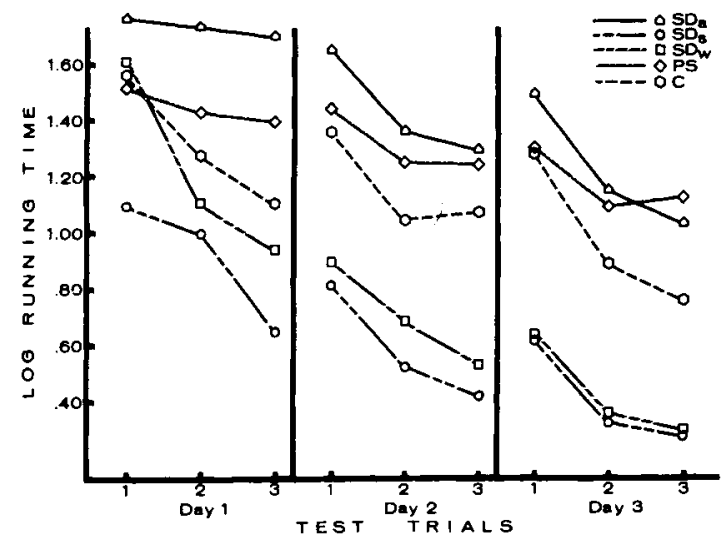

Fig. 1. Group log running times, averaged and analyzed for each trial, on each of the three days following initial test shock. $\mathbf{S D}_{\mathbf{a}}$, $\mathrm{SD}_{\mathrm{S}}, \mathrm{SD}_{\mathrm{w}}$. PS, and $\mathrm{C}$ represent prior treatment conditions consisting of sleep deprivations (SD) entailing enforced locomotion on an abrasive surface, SD involving locomotion on a smooth surface, SD induced by forced standing in deep water, preshock, and control respectively.

analysis of variance (cf. Winer, pp. 319f, 1962). The Fs for all main effects were significant, while none for the four interaction effects were (for groups, $F=4.42$, $\mathrm{df}=4 / 45, \mathrm{p}<.005$; for days, $\mathrm{F}=54.76, \mathrm{df}=1 / 45, \mathrm{p}<.001$, and for trials, $F=50.01, \mathrm{df}=1 / 45, \mathrm{p}<.001$ ).

A comparison between the weighted performance totals of the PSand $\mathrm{SD}_{\mathrm{a}}$ groups vs. the weighted totals of the remaining three was highly significant $(F=12.06$, $\mathrm{df}=1 / 45, \mathrm{p}=<.005)$. The only other significant $F$ resulting from grand mean comparisons was between the $C$ group vs. the weighted average of the $\mathrm{SD}_{\mathrm{W}}$ and $\mathrm{SD}_{\mathrm{S}}$ groups $(F=4.71, \mathrm{df}=1 / 45, \mathrm{p}=<.05)$.

A non-significant $F$ of $2.45(\mathrm{df}=4 / 45, \mathrm{p}<.05)$ for trial one of the second tèst session confirmed the success of the retraining procedure for equating group performances. A 5 by 5 factorial analysis of variance was employed to evaluate the data of this second set of punishment trials. The $F$ for groups $(F=6.69$, $\mathrm{df}=4 / 45, p<.001)$, and the $F$ for trials $(F=10.38$, $\mathrm{df}=1 / 45, \mathrm{p}<.005$ ) were highly significant, while the interaction was not.

The conclusions based on grand mean comparisons were, with one exception, identical to those revealed by the grand mean analyses for the first test session. The one exception was that, under weak punishment, performance of $\mathrm{Group} \mathrm{SD}_{\mathrm{a}}$ was indistinguishable from controls.

\section{Discussion}

Of the three SD conditions, the initial test punishment facilitated acquisition of the PAR only for Ss who had received the $\mathrm{SD}_{\mathrm{a}}$ treatment, clearly replicating the findings of Pearl et al (1964). In accord with the first of the four hypotheses put forth in the introduction, these results convincingly implicate the mediational significance of the cues resulting from the insult to foot tissues sustained both in the prior treatment and subsequent test situations by $\mathrm{Ss}$ of the $\mathrm{SD}_{\mathrm{a}}$ group.

Those treatments which involved only prolonged exercise and/or SD while minimizing macroscopic foot injury (the $\mathrm{SD}_{\mathrm{S}}$ and $\mathrm{SD}_{\mathrm{W}}$ groups, respectively) produced, if anything, an attenuation rather than facilitation of the acquisition of a PAR. That this latter finding is not solely attributable to the development of calloused or toughened paws by $\mathrm{Ss}$ of the $\mathrm{SD}_{\mathrm{S}}$ group (due to prolonged walking) is supported by the fact that Ss of the $\mathrm{SD}_{\mathrm{W}}$ group (who did not engage in walking) also exhibited an attenuated response to test punishment.

The results indicated that both $\mathrm{PS}$ and $\mathrm{SD}_{\mathrm{a}}$ treatments worked to produce similar, albeit non-identical, effects. In general, both treatments rendered $\mathrm{S}$ more vulnerable than controls to the disruptive effects of punishment. Conversely, the $\mathrm{SD}_{\mathrm{w}}$ and $\mathrm{SD}_{\mathrm{S}}$ treatments worked similarly to render $\mathrm{S}$ less responsive to later punishment. Indeed, these relationships were generally stable over two consecutive test sessions suggesting a certain permanency in the respective treatment effects. If correctly inferred from the data, there may exist a continuum of effect along a dimension of intensity or prior aversive stimulation (PAS). A certain amount of such treatment may work to "toughen" S to subsequent normally stressful encounters, while excessive amounts of PAS may have an opposite and debilitating effect.

\section{References}

Brown, J. S., \& Hoopes, J. J. A device for recording a rat's position in a straight alley. Amer. J. Psychol., 1965, 78, 130-133.

Kurtz, K. H., \& Pearl, J. The effects of prior fear experiences on acquired-drive learning. J, comp. physiol. Psychol., 1960, 53, 201-206.

Malmo, R. B. Anxiety and behavioral arousal. Psychol. Rev., 1957, 64, 276-287.

Pearl, J., Walter, G. C., \& Anderson, D. C. Suppression effects of aversive stimulation of subsequent punished behavior. Canad. J. Psychol., 1964, 18, 343-344.

Winer, B. J. Statistical principles in experimental design. New York: McGraw-Hill, 1962.

\section{Notes}

1. This study was supported in part by Grant MH 10876-01 from the National Institute of Mental Health, United States Public Health Service. Gertrude McIver gave valuable assistance in analysis of the data.

2. Now at Brigham Young University.

3. Now at Washburn University. 